\title{
CONSIDERAÇÕES SOBRE OS CONCEITOS DE NATUREZA, ESPAÇO E MORFOLOGIA EM ALEXANDER VON HUMBOLDT E A GÊNESE DA GEOGRAFIA FÍSICA MODERNA
}

\author{
Antonio Carlos Vitte* \\ Roberison Wittgenstein Dias da Silveira**
}

RESUMO:

O artigo discute a formação dos conceitos de natureza, espaço e morfologia na obra de Alexander von Humboldt e seus impactos na formação da geografia física moderna. Influenciado pelas reflexões de Kant na Crítica do juízo, pelos trabalhos de Goethe e de Schelling, Humboldt desenvolverá uma nova interpretação e representação para a natureza na superfície da Terra, em que o conceito de espacialidade será fundamental para a explicação dos fenômenos da natureza. A geografia física moderna estruturase com base em um complexo cruzamento de influências, tanto estéticas quanto instrumentais desenvolvidas por Humboldt, no qual o princípio da conexão será importante para a invenção artística e científica do conceito de paisagem geográfica.

\section{PALAVRAS-CHAVE:}

Humboldt; filosofia kantiana; Goethe; morfologia; geografia física.

\section{ABSTRACT:}

This article discusses the genesis of modern physical geography since the formation of the concepts of nature, space and morphology in the writings of Alexander von Humboldt. Influenced by the reflections of Kant in the "Critique of Judgment", the writings of Goethe and Schelling, Humboldt has developed a new interpretation and representation of nature in the earth's surface that turned the concept of space out to be crucial to the explanation of the phenomena of nature. A complex starting point of influences as such aesthetics or self developed instrumentals has structured modern Physical Geography through a principle of connection between artistic and scientific invention in the geographic concept of landscape.

\section{KEYWORDS:}

Humboldt; kantian philosophy; Goethe, morphology, physical geography.

\section{Introdução}

O objetivo deste artigo é discutir os conceitos de natureza, espaço e morfologia em Alexander von Humboldt (1764-1859) e sua influência na constituição da geografia física moderna. A premissa é a de que a geografia física é o produto das reflexões de Humboldt, provocadas pela necessidade de uma nova explicação metafísica sobre a superfície da Terra.

Segundo Barbara Maria Stafford (1984), o período de Alexander von Humboldt pode ser designado como sendo o da reunião do empirismo baconiano com o da estética kantiana desenvolvida por Goethe, cujo produto é uma nova representação da natureza e da superfície da terra. O julgamento estético deixa de ser metafórico, passa a ser uma linguagem artística, cuja representação imediata pode ser observada na cartografia, nos perfis biogeográficos e principalmente na pintura de paisagem (MENDOZA, 2006).

Motivado pelo princípio da experiência estética de Schiller (BEISER, 2005), Humboldt 
acredita que a pintura de paisagem é uma linguagem que também permite a pesquisa científica e ao mesmo tempo a educação do ser humano. A natureza-paisagem é o todo, que mediado pela estética, compreendida como uma totalidade viva e organizada, formada a partir das conexões, permite a constituição do todo, onde a observação e a contemplação teórica convertem o espetáculo estético em conhecimento científico. Segundo Ricotta (2003) esse princípio permitirá a Humboldt desenvolver a noção de espacialidade, considerada como uma das maiores invenções da modernidade.

Para Bowen (1981) essa transformação na interpretação da natureza proporcionada por Humboldt foi possível apenas devido às transformações na concepção de empirismo que já havia sido realizadas por Kant e pela Naturphilosophie, particularmente pela concepção metodológica de Goethe sobre o olhar e a observação e pelas concepções da filosofia-danatureza desenvolvidas por Schelling.

A ciência humboldtiana é o cruzamento de grandes transformações filosóficas, epistemológicas e empíricas provocadas pela ciência newtoniana, pelas transformações de substância e causalidade que foram desenvolvidas por Kant na Crítica do juízo em 1791 e aprofundadas por Goethe com base em suas leituras de Spinoza.

A geografia moderna, particularmente a geografia física, nasce a partir das reflexões da época de Humboldt, principalmente nas obras $O s$ quadros da natureza (HUMBOLDT, 1952) e Kosmos (HUMBOLDT, 1874), em que as noções de natureza e morfologia foram fundamentais para a constituição de uma nova interpretação da natureza e de sua espacialidade na superfície da Terra.

\section{A construção dos conceitos de espaço, natureza e morfologia em Alexander von Humboldt.}

A filosofia Crítica de Kant oferece, num primeiro aspecto, as bases de desenvolvimento para todas as ciências da natureza, a legitimação filosófica que define o que lhes cabe e que permite o reagrupar do empírico mediante princípios regulares universais, lei causais elementares. Com a Crítica da razão pura (KANT, 1999) Kant impõe uma mudança geral à maneira de filosofar, mas também um campo de sustentação para a ciência da natureza numa base newtoniana, articulada e levada a cabo com os Primeiros princípios metafísicos da ciência da natureza (KANT, 1990). Estabelece-se, nesse momento, uma ruptura entre sujeito e objeto pertinente ao interesse da razão na formulação de um conhecimento com validade objetiva para toda a experiência possível e que, desse modo, acaba por subscrever a natureza na esfera do condicionado, deixando à razão a possibilidade de agir livremente, ou seja, de exercer-se em seu interesse incondicionado sob toda representação do objeto externo. Espaço e tempo, como intuição pura, fundamentam a necessidade de considerar toda a experiência no limite dos fenômenos, além de reconhecê-los, enfim, como único domínio válido para um conhecimento com validade científica. Isso é importante em Humboldt na medida em que também faz parte deste propósito comum das ciências da natureza o esforço humboldtiano de valorização da experiência no trato científico, bem como o reconhecimento das técnicas e metodologias experimentais que ele liga apropriadamente num processo indutivo.

Doutra feita, a natureza, problematizada a partir do particular, do organismo como imagem-esquema de uma causalidade que não pode mais se restringir ao domínio do mecanicismo, representa a abertura para uma outra sistematicidade que, equiparando a finalidade na natureza com a finalidade na produção do homem como livre agente, reconhece, numa perspectiva técnica, uma teleologia do mundo natural. Todavia, com a Crítica da faculdade de julgar (KANT, 1995), Kant elabora uma nova forma de estabelecimento dos juízos que, se abrindo para além do caráter determinante da razão, se apresentam em uma perspectiva reflexiva. Fundamental, essa perspectiva reflexiva, estabelecida no valor 
universal dado ao juízo de gosto estético na contemplação do belo, se estende para a natureza e encontra nesta uma teleologia independente da razão e, portanto, que exige um princípio regulador independente. Nisso funda-se uma teleologia que não é mais dependente da analogia com a produção técnica, haja vista a possibilidade de se enxergar uma finalidade na natureza que produz não por determinação do geral pelo particular, mas que, pelo papel da estética e da forma, apresenta uma natureza segundo uma finalidade-sem-fim (KANT, 1995). Logo, a finalidade não está associada com qualquer produção intencional na perspectiva racional; o elemento técnico, aquele de um agente determinando de cima para baixo a finalidade é abandonado na visão de uma natureza com finalidade independente. A sistematicidade que advém da Crítica do Juízo (KANT, 1995) resulta na consideração de um princípio independente no telos natural, levando Kant a pensar uma reaproximação com as ideias de Leibniz e, desse modo, a possibilidade de reunir os casos particulares com uma finalidade do mundo natural. Isso é recuperado por Humboldt sob uma nova roupagem romântica.

O romantismo representa na formação dos conceitos de espaço, natureza e morfologia o caminho pelo qual Humboldt pensará uma ciência que tem em seus princípios, e mesmo no seu método, um caminho diverso do empreendido pelo racionalismo na ciência da natureza. Os conceitos de que se valerá, em igual medida, remetem ao itinerário científico-filosófico: KantGoethe-Schelling. O romantismo permite a Humboldt o desafio de percorrer o Cosmos, de definir em seus trabalhos o liame entre orgânico e inorgânico que advém de Schelling; permite a busca do protótipo e do protofenômeno na finitude, na comparação exaustiva que exige o método goetheano; torna possível a junção dos opostos pelo fio condutor de uma idealidade da natureza na valorização da vida, da força vital no Gênio Ródio; o Romantismo torna ainda necessário nos remetermos à arte, à busca do equilíbrio dinâmico entre os opostos na junção do que é em Schelling a intuição intelectual e estética, refletida na forma com que Humboldt trabalha o conteúdo da análise; enfim, os conceitos que nos propomos a investigar reagrupam um vasto terreno filosófico-científicoartístico que vão de Kant ao movimento primeiro romântico. O primeiro passo na conclusão desse trabalho é, portanto, a exposição do arranjo sistemático da ciência humboldtiana à luz dos conceitos de espaço, natureza e morfologia. E de que maneira estes conceitos permitem um reagrupar metodológico no projeto de ciência humboldtiano.

O conceito de espaço é um dos pontos centrais na compreensão sistemática de Humboldt e, com ele, da Gênese da Geografia Moderna.

O empírico deve ser o universo de toda a ciência da natureza, esse é um preceito fundamentado por Kant e incorporado por Humboldt, assim como por todas as ciências dessa ordem. Fundamental, essa adoção indispensável se liga a uma concepção de espaço na filosofia de Kant, a que define o campo objetivo como aquele compreendido dentro da possibilidade intuitiva a priori do sujeito. Em termos simples, é o espaço absoluto, anterior e condição do campo dos fenômenos. Não podemos, contudo, dizer que este seja o fundamento de um espaço geográfico em Humboldt, exceto quando consideramos a sua adoção como categoria, ou seja, quando o espaço, tomado como absoluto, perpassa a experiência possível na compreensão categorial das distribuições, variações e apresentações do universo empírico, enfim, quando serve de categoria analítica para o estudo do empírico. Nesse sentido estrito, o espaço é absoluto, como não poderia deixar de ser quando tomado como categoria de análise. Entretanto, a construção de uma espacialidade em Humboldt se atrela às transformações que ele incorpora na apresentação de sua ciência.

Humboldt incorpora uma visão de natureza goethe-schellinguiana e, nessa incorporação, remete-se a uma noção de espaço relativo próxima à construída por Leibniz. O conceito leibniziano de mônada é incorporado na construção do método morfológico de Goethe e que, assim como Leibniz, pensará a realidade a partir de uma ligação entre a expansão e a 
contração. "Tudo o que se gera procura o seu espaço e quer duração. É por isso que expulsa qualquer outra coisa do lugar que ocupa e the encurta a duração." (GOETHE, 2000 , p. 15). A expansão, como admitira Leibniz pela apetição interna às mônadas, procura estender seu domínio, desta feita, avança, de acordo com seu grau, para o domínio das outras mônadas. Cada mônada procura a máxima realização do que há nela em germe, procura o máximo de sua duração e extensão, desse modo é que podemos entender a primeira parte da sentença de Goethe : "Tudo o que se gera procura o seu espaço e quer duração" (GOETHE, 2000, p. 15). Se for de um grau superior ascende sobre as demais expulsandoas dos seus lugares e encurtando-Ihes a duração. Goethe retrata aqui a ideia leibniziana que fundamenta a noção de espaço e tempo. Podemos então conceber que se trata de uma perspectiva dinâmica de ambos, que se associam na visão de Goethe a partir de uma perspectiva ontológica. $O$ valor dado à experiência na proposta goetheana deixa transparecer uma visão que aproxima as mudanças ocorridas no campo dos fenômenos com a formação do espaço e do tempo. Goethe claramente se liga aos propósitos de uma epistême moderna: anuncia em seu método a perspectiva de uma dinâmica que repousa na própria essência do ser; busca em seu itinerário científico-filosófico-artístico uma fundamentação ontológica. Essa busca, herdeira da Crítica da faculdade de julgar (KANT, 1995) em vista da autonomia sistemática dada à natureza com relação à razão, permite, como vimos na consideração do espaço em Kant, um repensar capaz de associar as variações, os particulares, com a construção do espaço, indo além dos ditames a priori de um transcendental no sujeito.

Entender o espaço humboldtiano é compreender toda a conexão pretendida entre estes diferentes legados. O espaço em Humboldt não é nem uma plena abstração nem uma coisaem-si empírica. Como termo médio entre estas duas concepções, o espaço revelar-se-á à intuição pela ligação existente entre tudo o que compõem o Cosmos. A mente responderá pela ordenação e regulamentação do que se apresenta de maneira multiforme; não a, como podemos notar, um abandono da racionalidade, contudo, ela não basta, necessita e pressupõe um conjunto de fenômenos e dinâmicas que se ligam não a esta ordenação colocada, mas à fonte única e comunicável de toda a realidade, aquilo que perpassa a intuição intelectual e a natureza (RICOTTA, 2003). Humboldt ratificará neste ponto os sentidos de sua ciência: não só um empreendimento guiado ao conhecimento objetivo do mundo, mas um desafio na busca de uma causa subjacente aos fenômenos; uma causa que se apresentará na leitura artística e científica da forma, por ser ela sintetizadora do jogo dinâmico de correspondência entre tudo o que compõe a natureza e a parte que se configura. A espacialidade é, portanto, capaz de retratar o desafio integrador de Humboldt; é por ela que podemos enxergar de maneira mais clara a perspectiva de uma superação da análise fundamentada em categorias universais, ao mesmo tempo em que não se vê ignorada uma generalidade abstraída de todo o particular.

Outro conceito fundamental é o de natureza (SILVEIRA, 2007), em que as diferentes concepções que se estruturam sob este conceito confluem para uma noção geral ligada à Naturphilophie dos românticos. O primeiro caminho na construção desse conceito no sentido final que assume na obra de Humboldt é dado pela colocação de uma teleologia da natureza em Kant. Tratada em autonomia com relação aos determinantes da razão, a natureza se apresenta com um telos próprio, independente do que pode ser colocado por qualquer imperativo do sujeito ou relacionado com uma produção técnica. Essa noção basilar, incorporada pelo movimento romântico, assume formas mais claras na filosofia de Schelling e na construção de Goethe. A representação dessa concepção de natureza é o organismo, com suas partes interdependentes e ordenando por uma finalidade comum o desenvolvimento geral que é, em última instância, dada por um desenvolvimento que pressupõe um campo causal não-linear, em que todo e partes dialogam a todo instante na construção das formas. Essa visão reagrupa a concepção de um protótipo goetheano, pelo qual um modelo universal subjaz a apresentação variada e 
particular no reino das formas, com a visão de um protofenômeno, uma força pela qual se põe em marcha o processo ininterrupto de uma metamorfose da natureza, uma dinâmica que é colocada por esse princípio que é fim.

Em igual medida, a concepção de natureza incorporada por Humboldt considera um elemento unificador que liga o desenvolvimento natural com o do espírito, aquilo que aparece na filosofia da natureza de Schelling como o ponto comum destes dois domínios aparentemente contrapostos. A idealidade da natureza permite conceber o homem como momento de síntese do próprio desenvolvimento da natureza, ou seja, o espírito, unificado pelo elemento ideal, aparece como a tomada de consciência da natureza por ela mesma. Essa visão é fundamental na construção humboldtiana de uma ciência que busca reunir um múltiplo legado e reconhecer nas obras do homem um ponto fundamental no esforço de compreensão da natureza. Igualmente relevante é a ligação que se estabelece entre orgânico e inorgânico a partir ainda desse elemento unificador da natureza. Como força Vital em Humboldt, posteriormente modificada em um processo de desmistificação e incorporação ontológica, este elemento unificador é a chave para compreender a relação entre as associações do relevo e do clima com a formação vegetal e sua distribuição nas diferentes regiões do planeta. Estruturante, essa concepção de natureza é o ponto nodal de tudo o que pretende Humboldt ordenar em nome de uma lei geral ou de uma conexão dos elementos do Cosmos.

O conceito de morfologia, por sua vez, conflui o processo dinâmico da natureza na concepção da forma. É a forma que será responsável por revelar à intuição a correspondência no instante entre todo e partes e, desse modo, colocar-se como elemento indispensável no valor dado à arte. Assim como os outros conceitos, esta valorização da forma parte de Kant, sendo incorporada pelos românticos e por Humboldt na construção de uma valorização estética e no reconhecimento do papel da intuição. A forma representa a unificação da dinâmica no instante e, desse modo, com a consideração de uma ligação entre sujeito e objeto pelas vias da intuição, se distancia do caráter determinante da razão e sua ordenação. Isso será fundamental na proposta de Goethe e na sua análise da natureza, afinal, é a forma quem representa objetivamente aquela dinâmica e variação imposta pelos ideais de protofenômeno e protótipo. A forma é lugar de síntese, unificação da dinâmica da natureza; em conjunto, é tratada morfologicamente, afinal, aqui se evoca a tarefa de abarcar um jogo de relações pela captura intuitiva da imagem da forma, nesse caso, do conjunto das formas. Importante, esta morfologia é tratada por Humboldt na observação da paisagem, na descrição dos Quadros naturais, que, no sentido último, são pinturas de um processo, de uma dinâmica que toma expressão mais elevada nas condições originais de sua manifestação, na fidedigna contemplação do conjunto das formas. Fruto não só de uma relação momentânea, a morfologia compreende o processo histórico de construção das formas, engloba as transformações num capturar intuitivo. Os domínios morfológicos do relevo, da vegetação, expõem para Humboldt o processo de construção bem como a dinâmica que subjaz a natureza em seu processo de formaçãotransformação contínua.

Indissociável desta concepção é a noção de arte, afinal, é ela que permite a representação do que não se pode exprimir, do que se apresenta meramente como intuição intelectual. Aqui, a intuição estética cumpre seu papel na medida em que pode tornar objetiva a dinâmica da natureza na forma, pela figura do gênio, sem se limitar à simples ordenação analítica da razão. Pintar o conjunto das formas em máxima conformidade com a realidade é parte desse método morfológico que se estrutura em Goethe e que é habilmente apropriado por Humboldt, afinal, esta representação reflete o que de outra forma não se pode traduzir, aquilo para o que nossos dispositivos formais se constrangem e se limitam.

Podemos agora, diante das concepções de espaço, natureza e morfologia, entender que no projeto de ciência de humboldtiana, a experiência, é tudo quanto nos cabe como domínio de análise, 
é nela e por ela, enfim, que devemos nos esforçar em percorrer os detalhes, em nos dispormos satisfatoriamente a um número considerável de particulares, ou seja, de condições específicas, que são representadas pelos estudos regionais.

O desafio enciclopédico encontra sua legitimidade nesse valor dado ao empírico. A experiência é o campo válido na estrutura das ciências, afinal, é ela, que nos permite operar nos limites da razão.

Não obstante se trate do empírico, há de se reconhecer uma ligação entre os fenômenos, seja ela uma condição a priori, como no caso de Kant, ou uma condição do próprio processo de formação-transformação da natureza, como em Goethe e Schelling.Logo, devemos buscar as leis e os princípios causais, que, para Humboldt, é uma tarefa indissociável das ciências da natureza.

Mas há nesse momento um passo importante na incorporação das metodologias: a concepção de homem. Humboldt concebe o homem como médio entre razão e sensibilidade, assim como aponta Schiller, e, desse modo, pode articular coerentemente dois domínios que se apresentam antagônicos: o da racionalidade e o da sensibilidade. Esse é um passo estruturante, é a possibilidade aberta de uma confluência inovadora, o olhar do gênio que antevê muito mais do que um agrupamento aleatório destes campos contrapostos. Com sua concepção de homem, Humboldt dá um passo adiante na construção de sua ciência: incorpora sem culpa todo o ferramental técnico-metodológico das ciências racionalistas em plena ascensão, haja vista a consideração de que o domínio da razão deve ser também considerado na edificação do conhecimento; doutra feita, abre os olhos para o que está além desta racionalidade posta, afinal, pela medida da sensibilidade, deve tocar o homem a impressão no contato com a natureza, o sentir que não procura ordenação ou encadeamento lógico, mas que simplesmente se impregna na existência de quem se propõe o contato. Existir é a medida dessa sensibilidade; existir em comunhão com as coisas, em ligação com elas; sentir antes de pensar; conceber que não se pode considerar o que está fora sem remeter-se a si mesmo, ao que pulsa internamente no ser.

Este ser é a medida de um saber que não pode ser exprimido, não pode ser comunicado pela voz da ciência, de suas máximas, de suas leis e ordenações regulares; não há um plano de causas e efeitos, tudo é plena relação; não se pode medir o que de si está fora e o que de fora está no ser. Essa sensibilidade não é comunicável, não é exprimível pela voz da razão, mas é, como ela, medida da realidade, existe como parte de nós, do que nos toma. Conhecer é mais do que ordenar, é também considerar essa imponderação inarticulável. A tarefa, difícil de antemão, a de explicar o mundo, a natureza, ganha nova dimensão, já não é explicar o mundo, é explicar a si no processo de construção do mundo; é explicar a natureza no seu diálogo formador com o humano. Como aponta Ricotta (2003), os limites na compreensão do mundo são as bases necessárias para o cenário da imaginação, aquilo que torna humana a interpretação da natureza.

Sem pudor, o que não se pode exprimir encontra expressão, canaliza seus sentidos em articulação com os recursos possíveis de uma razão valiosa. Fala a sensibilidade em diálogo aberto com a razão na execução do elemento estético, na construção objetiva da obra de arte. A ligação que une o objeto a seu observador pode enfim aquietar-se, pode encontrar alento e representação na arte genial. Na arte, a natureza e o humano já não estão desarticulados, constituem um único, uma unidade que tanto incita a razão como a sensibilidade; não há mais a dificuldade de se pensar dois domínios antagônicos, a síntese está realizada, cumprida no seu grau mais elevado. Como em um par dialético, natureza e homem se associam, cumprem o que lhes incita o próprio da existência, esse fim que é o princípio de ordenação: a força vital, o ideal que perpassa tanto o inconsciente como a consciência. Para além de uma realização humana, esse representar do mundo é a própria atividade desse elemento unificador; ou seja, é a força imposta ao mundo; é a natureza manifestando-se pela sua mais alta voz: a humana. 
Enquanto síntese, essa arte de representar a dinâmica do mundo é tarefa dos grandes espíritos, é matéria do gênio, daquele para quem o domínio da razão eleva-se às alturas e que, ao mesmo tempo, o domínio da sensibilidade transborda na figura da representação do Cosmos. Já não há limites; mesmo conhecer já não é a tarefa central, enfim, acaba em plena forma a matéria bruta falando por si, emoldurando-se de uma finalidade que ultrapassa a cega tomada de uma explicação possível para a sua composição. Esse sonho é o caminho que se coloca toda a atividade do mundo; é a expressão de uma ininterrupta aproximação de um ideal que é o germe.

Na contramão de tudo o que conhecemos hoje sob o nome de Ciência ou mesmo de conhecimento, esse devaneio é o devaneio de Humboldt; uma vertigem real que não pode ser consumada em uma vida, porque é a própria edificação do sentido da realidade. Incontida em duras formas, a ciência humboldtiana é a abertura não do espírito humano para esses novos pensamentos, mas a voz de uma natureza que toma forma humana, que reencontra no uso de uma linguagem proso-poética, na construção da bela forma, a interlocução de um processo que é a medida de toda a relação universal. O Cosmos, essa obra que chamamos outrora de loucura sob forma de ciência, é a tentativa de tornar científica aquela voz que só se ousou pronunciar na medida do dom artístico. Sem ingenuidade, Humboldt sabia do seu desafio; tinha clara dimensão do que estava realizando

La descripcion del mundo, considerado como objeto de los sentidos esteriores, necesita indubitablelmente del concurso de la física general, y de la historia natural descriptiva; pero la contemplacion de las cosas creadas, enlazadas entre si y formando un todo animado por fuerzas interiores, dá a la ciencia que nos ocupa en esta obra un carácter particular. (HUMBOLDT, 1874, p. 40 - 44)

Aqui, na medida definitiva de uma articulação de múltiplos legados, se edifica a proposta de Humboldt; aqui, na proposta de Humboldt, se apresenta a ciência geográfica como síntese dessa alquimia universal no plano da empiricidade e sob as categorias do espaço e da paisagem e numa perspectiva de análise regional.

\section{Humboldt \\ A Gênese da Geografia Moderna em}

\section{As premissas da leitura}

A Geografia Moderna está em Humboldt, nele se alojam os princípios fundamentais de uma ciência com método, metodologias e um objeto próprio, tão próprio e singular que seu desenvolvimento resta confuso e claudicante.

Mas o que disso tudo é Geografia? O que de Humboldt está verdadeiramente ligado ao processo de construção de uma Geografia Moderna? O ponto central para análise do que é Geografia em Humboldt parte de dois pressupostos centrais: o primeiro diz respeito ao que concebemos como Geografia, o segundo, está ligado à discussão em torno da origem das ciências a partir de múltiplos legados. Este último ponto é, em alguma medida, óbvio, mas nos interessa na análise da recusa de Capel (1982) no que se refere a uma gênese da Geografia Moderna em Humboldt.

Com relação ao primeiro ponto, reforçamos a concepção de que entender a história da Geografia é situar-se diante do conhecimento geográfico que se produz e, paradoxalmente, posicionar-se acerca da Geografia é reconhecer-se com sobriedade no cenário de construção histórica. Ora, só podemos avaliar o que é Geografia em Humboldt se reconhecermos o que é Geografia. Tendo claro o que compreendemos por Geografia, poderemos responder com objetividade ao desafio de delimitar com segurança o que de Humboldt está no domínio desta ciência, bem como o que de sua construção metodológica foi estruturante para a nossa forma de construção científica. Difícil, essa tarefa nos remete àquela pergunta embaraçosa: o que é Geografia? Com desconforto, enfrentamos esta questão com a certeza não de uma resposta pronta, mas de uma busca que encontra nesse momento uma necessidade de exprimir-se para o bom andamento das reflexões e análises. 
De modo geral a Geografia pode ser concebida como a ciência que estuda o espaço, não um espaço puro e simples, mas este que se constrói com base na articulação dos elementos naturais e humanos. O espaço geográfico é aqui a medida de uma relação, seja entre os elementos da natureza, seja entre esta natureza e a sociedade. Nesse momento, nenhuma grande dificuldade parece evocada, afinal, é quase ponto comum que aquilo que acaba de ser exprimido compreende a ciência geográfica e a define até com alguma clareza. Mas a tranquilidade é aparente, para além dela se apresentam, com esta descrição clara, uma série de problemas. 0 primeiro deles é de definição, afinal, se a Geografia é essa produção e representação do espaço a partir das conexões dos elementos da natureza e destes com a sociedade, se faz mister definir o que é então essa natureza e o que é, por fim, essa sociedade. Aqui as coisas se tornam mais difíceis, afinal, intentar uma resposta para estes conceitos não é tarefa fácil, ainda que seja possível; todavia, esclarecemos que confluir as premissas metodológicas destas duas definições é certamente um trabalho filosófico árduo. Ora, foi justamente este um dos problemas que procuramos destacar na construção da Geografia e na sua divisão histórica entre uma Geografia Humana e outra Física. O valor dado a um dos elementos, na verdade, a definição que engloba o outro termo no seu domínio, é a dificuldade da dualidade geográfica no que se refere ao seu caráter físico e humano. Quer dizer simplesmente que ao se estabelecer uma base filosófica comum, tarefa indispensável ao desenvolvimento coerente das propostas metodológicas, incorreu-se historicamente no erro de ou valorizar em demasia a natureza, aparecendo o elemento humano como uma variável a ser incorporada numa análise sistemática, ou no equívoco de dar ênfase à sociedade e suas formas de organização produtivas, considerando a natureza como um elemento incorporado na lógica geral de uma ordenação econômica e seus rebatimentos culturais e políticos. Essa dualidade é a medida do problema filosófico de agrupar de forma plenamente satisfatória a natureza e a sociedade sem violar premissas filosóficas ou articular uma série de correntes contrapostas e divergentes.
Não podemos deixar esta pergunta sem resposta se pretendemos analisar a obra humboldtiana e reconhecer nela um caráter geográfico, afinal, como frisamos, precisamos esclarecer o que é para nós Geografia. No limite que compete a uma exposição como essa, nos valemos do que foi aqui apresentado, ou seja, colocamos como uma possível resposta a este embaraço filosófico para a Geografia, a resposta dada outrora pelo movimento romântico a esta dualidade entre natureza e espírito. Filosoficamente falando, a tarefa do romantismo advém da dualidade colocada pelo projeto Crítico kantiana, aquele da separação entre sujeito e objeto e a concepção de homem e natureza. Esse problema, enfrentado anteriormente pelo próprio Kant, e levado a cabo pelos românticos, é fonte de inúmeras reflexões que podem dar nova carga conceitual a esta tarefa difícil de compreensão da Geografia. É evidente que esta filosofia não nos cabe na justa medida, pelo fato claro e evidente de que são outras as condições intelectuais e materiais depois de mais de um século de produção do conhecimento. Assim, entendemos que a aproximação disposta entre homem e natureza na Naturphilosophie é matéria de interesse para a Geografia, sem esquecer, contudo, a parcialidade que the cabe em um novo contexto.

A Geografia nos parece, desse modo, o campo de aproximação destes dois domínios, o do humano e o da natureza e, por esse caminho, concebemos que a filosofia da natureza dos românticos oferece um aporte significativo no desafio de se ligar em um processo histórico e unificador tanto as transformações da natureza como a ligação destas com o desenvolvimento da atividade do homem, aqui concebido socialmente, ou seja, assumindo uma roupagem histórica e específica, segundo o lugar e as condições em que se apresenta.

Mas há, ainda dentro do universo de definição da Geografia, um segundo problema, o do objeto e sua ligação com os objetivos. Colocamos inicialmente que a Geografia se ocupa do espaço, um espaço geográfico, e, como tal, não resta aqui nenhum desafio maior. Contudo, 
aqui se coloca uma dificuldade, qual seja, a da perspectiva a ser tomada no trato desse objeto. No primeiro capítulo apontamos para este problema, colocamos a dificuldade assumida historicamente de se pensar o espaço não só objetivamente, mas no seu rebatimento subjetivo. A Geografia não pretende somente analisar as relações da natureza e destas com a sociedade no plano de disposição empírica, objetiva, ela pretende, igualmente, identificar o que dessa disposição objetiva rebate na construção cultural e social, enfim, na perspectiva subjetiva. Isso é um desafio filosófico, mas para o qual a Geografia apresentou uma resposta em certa medida satisfatória, com a incorporação dos princípios e fundamentos de um materialismo dialético; no qual se pode compreender tanto a dimensão objetiva como a dimensão subjetiva em um contínuo processo de construção e reconstrução, um duplo influenciar que fundamenta uma análise com domínios científicos válidos. Contudo, resta problemática esta proposta, na medida em que se coloca, no plano filosófico, uma dificuldade que viola o princípio elementar dessa dupla influência, o da liberdade. Essa liberdade é suprimida do par dialético no momento em que se evoca um caráter constitutivo para a materialidade e coloca-se a sua primazia, contra a qual nenhuma arquitetada relação aberta entre homem e natureza pode negar a estruturação causal que aponta o vindouro como causado pelo precedente. Essa medida de uma temporalidade fluindo em meio a essa dinâmica de uma materialidade constitutiva encerra as cadeias da liberdade, aprisiona o homem, a sociedade, aos ditames primeiros de uma matéria que é origem de toda a transformação. Moreira (2006) aponta outros caminhos também para o saber geográfico nessa tentativa de aproximar subjetividade e objetividade na consideração do objeto da Geografia, como o caso da fenomenologia, por exemplo. De modo geral, Moreira aponta para esse caminho, a busca dentro da Geografia de um saber integrador, que busca unidade, uma visão "holística", como ele mesmo define.

Sem pretender uma resposta definitiva para esse processo, nossa concepção de Geografia, segundo o limite de interpretação que nos cabe, não pôde encontrar uma resposta satisfatória à aproximação entre objetividade e subjetividade, restando esta uma dificuldade a ser melhor conduzida, para além do caráter determinante de um ou outro elemento tomada em sua primazia ou admitido constitutivamente, quer, dizer, de maneira dogmática. $\mathrm{Na}$ Naturphilosophie, que poderia ainda oferecer um novo horizonte de análise, se apresenta o problema inverso, a primazia de uma idealidade que dificulta, definitivamente, uma adoção irrestrita, se mostrando evidente uma necessária reformulação estrutural das premissas que só a filosofia pode dar. Enfim, é um problema de grandes proporções para o qual nos apresentamos, como os outros, sem uma resposta acabada, sobretudo no que se refere à aplicação no universo de análise geográfica.

\section{O papel de Humboldt na gênese da ciência geográfica}

Podemos identificar uma linha direta que liga Humboldt à Geografia, notadamente uma Geografia Física na qual se dispõem uma série de observações e conexões na composição de Quadros linguísticos da paisagem e da região. Claval (2000), inclusive, aponta Humboldt como um dos fundadores deste ramo regional da ciência geográfica. Assim, cada parte da Terra representa um conjunto complexo de fatores que podem ser associados e reduzidos mediante leis ou princípios gerais. Os casos particulares caracterizam as regiões; cada uma delas é disposta por diferentes características, segundo o clima, o tipo de relevo, a vegetação e, nesse rumo, cada uma destas partes é correlata à totalidade, uma compreensão orgânica de um planeta cujas teceduras traduzem uma ligação irrestrita.

Além das vantagens especiais que Ihes são próprias, cada zona tem também o seu caráter determinado. Deixando certa liberdade ao desenvolvimento anómalo das partes, o organismo, em virtude de um poder primordial, submete todos os seres animados e todas as plantas a tipos definidos que se reproduzem eternamente (HUMBOLDT, 1952, p. 283). 
Aqui há a apresentação de um princípio que é fundamental para a Gênese da Geografia Moderna, o de uma ligação entre os particulares com uma conexão geral, uma ligação estrutural entre os elementos que compõem a natureza. Isso é geográfico, independente do valor que se dê ou da medida metodológica empregada: seja por arranjos de palavras que pretendem revelar um medium-de-reflexão no uso da linguagem prosopoética, seja pela conexão sob elementos unificadores. Não se trata aqui simplesmente de situar os fenômenos, nem de descrevê-los pura e simplesmente, o que se coloca é uma ligação fundamentada num método comparativo, em que o exame das diferentes partes da Terra fornecem elementos suficientes para a aferição de princípios regulares de ordenação, ao tempo que também revelam a particularidade em função de específicas variações mediante estes princípios gerais. Humboldt, nas duas passagens a seguir, resume apropriadamente este desafio comparativo:

Estas dos envueltas de nuestro globo, el aire y el agua, constituyen un conjunto natural, y á ellas debe la superfície de la tierra la variedad de los climas, segun las relaciones de estension superficial de la tierra y del mar, segun la forma articulada y orientacion de los continentes, segun la altura y direccion de las cadenas de montañas (HUMBOLDT, 1874, p. 268).

E mais a diante:

Tales son los principales datos que deben tenerse en cuenta cuando se trata de comparar las superfícies respectivas de la tierra firme $y$ del mar, y de estudiar la influencia que estas relaciones ejercen sobre la distribuicion de las temperaturas, las presiones variables de la atmósfera, la direccion de los vientos, el estado higrométrico del aire, y por conseguinte sobre el desarollo de la vegetacion (HUMBOLDT, 1874, p. 269).

Isso é, certamente, produzir Geografia, com recursos e limites cientificamente válidos. A polêmica, nessa questão, assenta na questão deste método comparativo, afinal, ele não é pura e simplesmente a representação geral dos esforços das ciências racionalistas do período; por detrás deste método está a concepção goetheana de um protótipo, um modelo ideal que subjaz às variadas formas. Os elementos de ligação não são apenas as leis regulares do clima em associação com o relevo ou uma relação entre maritimidade e continentalidade, o que se coloca em cena é a apresentação de uma comparação que leva em conta um modelo ideal, pelo qual se pode derivar ou pressupor as particularidades. Comparar, em Humboldt, é também buscar esse elemento ideal unificador. Seja como for, essa proposta entra nas vias dispostas por uma ciência moderna, na medida em que este método assenta-se no elemento estruturante da experiência e a partir dela consagra princípios com validade objetiva para o campo dos fenômenos. Independente do nome que se dê naquele contexto, ou de como se reconheça Humboldt neste processo, essa construção é geográfica.

Ainda no plano direto e menos polêmico, podemos apontar a produção de representações gráficas e cartográficas de Humboldt, no traçar de isolinhas, na localização das estruturas minerais ou ainda na produção dos perfis topográficos, como caminhos para estruturação de uma Geografia com domínios, métodos e metodologias próprios. Essa tarefa, ligada a princípio aos ditames gerais da ciência racionalista, veicula informações com uma conexão e análise geográfica subjacente. Traçar isolinhas, por exemplo, é reconhecer elementos unificadores de determinada área e dispor essa conexão cartograficamente, ou seja, há aí uma ligação entre os particulares, e mais, há uma capacidade de enxergar a regularidade que os envolve. Essa produção de uma cartografia temática é, sem maiores controvérsias, uma contribuição geográfica. Doutra feita, a representação procura ser a manifestação da perspectiva intuitiva, a apreensão da totalidade no instante, na captura da forma que é síntese, enfim, aquele legado goetheano apontado nos capítulos anteriores. A presença das pinturas como elementos de representação, como as de Hackert (VALADÃO, 2008), por exemplo, traduzem tanto este processo de captação da totalidade no instante pela reprodução detalhada 
e fidedigna das formas em conjunto (morfologia e paisagem) como a tarefa de trazer o elemento humano no processo de produção da natureza. Recolhida sob a forma artística, a imagem é o avanço da imaginação para onde os domínios formais da razão não podem se estender, é a cobertura geral de uma realidade que não pode dissociar-se desse jogo aberto entre a natureza e o espírito que com ela se relaciona.

Quanto aos perfis topográficos, os mesmos têm um duplo mote: tanto demonstrar o interesse objetivo de uma ciência aplicada à análise empírica, voltada a compreensão dos elementos que compõem a paisagem, como o de revelar os processos de contínua transformação e construção-reconstrução pelas formas. As sobreposições revelam uma história, uma natureza que muda de feição, ainda que essa dinâmica passe desapercebida àquele que não pode conceber a atividade que a todo momento revoluciona a esfera do inorgânico. Há aqui a visão de uma forma como produto e como produtora. A tarefa de dissecar mediante uma representação gráfica demonstra analiticamente o quanto desta forma se revolucionou no seu processo histórico; por outro lado, a tarefa de tomar a estrutura em conjunto permite considerar a forma na sua função ativa de síntese no globo, ou seja, as feições se consagram na morfologia da paisagem como momento acabado de unificação dos elementos pela captação intuitiva da cena. Isso também é Geografia; é à base de um conhecimento geomorfológico levado a cabo com o curso da Geografia na Alemanha. Não são considerados os elementos estritamente geológicos, nem somente a ação dos agentes do clima, há uma ligação pressuposta na concepção morfológica do relevo em Humboldt; uma ligação entre orgânico e inorgânico.

Humboldt também se preocupou com uma distribuição da vegetação; uma disposição das plantas no globo em função também de regularidades e particularidades sempre em conexão. As plantas, como vimos, são compreendidas naquele sentido goetheano, estão em contínua metamorfose e revelam na forma o que está contido em germe e o que se dispõe como condição ambiente. Esse ideal regulador, esse infinito em comunicação com o finito, tomado na visão da forma é incorporado por Humboldt; nesse caso, trabalhando com maior detalhamento as condições de variação climática e de relevo como forma de definir o predomínio de determinados grupos de plantas, bem como o maior ou menor desenvolvimento em determinadas condições. Estes estudos são o passo necessário para se pensar a distribuição da vegetação tomada em conjunto, não isolada simplesmente na planta, é, enfim, uma etapa que antecede, no maior detalhamento, o processo que culmina no que seria uma análise geral das vegetações predominantes, sem, contudo, se desvincular do caráter central do método, que pressupõe, em última instância, o papel da intuição. Segundo Humboldt (1874): "(...) a criação vegetal atinge a imaginação pela amplitude de suas formas sempre presentes em cuja massa se revela a antigüidade ligada, por um privilégio especial, com a expressão de uma força sem cessar renovada." (HUMBOLDT, 1874, p. 331-332- tradução nossa) Nesses diferentes níveis e suas relações é que Humboldt pode estabelecer o que deve ser agrupado e o que deve ser divergido na distribuição da vegetação ou no estabelecimento das suas disposições regulares. Na conclusão do Livro IV, no segundo volume dos Quadros da Natureza, Humboldt (1952) resume apropriadamente estas considerações:

Ao esboçar, nos quadros anteriores, a fisionomia das plantas, propus-me, sobretudo, três fins intimamente ligados: quis fazer ressaltar a diferença absoluta das formas; indicar a sua relação numérica, quer dizer o lugar que ocupam, nesta ou naquela região, na massa total das plantas fanerogâmicas; e, ultimamente, a sua distribuição geográfica, segundo a latitude e o clima. Quando nos desejamos elevar a concepções gerais acerca das formas vivas, não se deve separar, julgo eu, o estudo das relações numéricas e o da fisionomia. Também se não deve limitar o estudo da fisionomia das plantas aos contrastes que os organismos apresentam, considerados isoladamente; há que procurar descobrir leis que determinam a fisionomia da natureza em 
geral, os diversoss caracteres que a vegetação comunica às paisagens em toda a superfície do globo, e a impressão viva que produzem a reunião e o contraste de formas opostas, em zonas que diferem em latitude e elevação. (HUMBOLDT, 1952, p. 135).

Isso também é produzir Geografia, afinal, reconhecer estes domínios vegetais na sua distribuição segundo princípios gerais, agrupando e divergindo em função de um método próprio de reconhecimento pela forma em seu conjunto é pensar geograficamente.

Essa vegetação é ainda tomada num sentido histórico, ou seja, ela está diretamente relacionada aos diferentes tipos de condição que dominaram o planeta. " A história da camada vegetal e da sua propagação sucessiva sobre a crosta escalvada da terra tem as suas épocas, do mesmo modo que a história das emigrações que disseminaram pelas diversas regiões, os animais e as plantas" (HUMBOLDT, 1952, p. 279). Papel importante tem a filosofia da natureza nessa concepção histórica, segundo Humboldt (1952): "Rodeada por fenômenos variáveis, o observador, que se consagra ao estudo da filosofia da natureza, trata sem cessar de ligar o presente ao passado." (HUMBOLDT, 1952, p. 168). É a consagração de uma ideia de natureza em contínua transformação em um processo de construção ininterrupta e dinâmica.

Ao norte do nosso continente estão sepultados no interior da terra troncos de palmeiras e esqueletos de elefantes; e, segundo a sua posição, pode conjecturar-se que não foram levados dos trópicos aos pólos por correntes, mas sim que, nas grandes revoluções do nosso planeta, os climas passaram por mudanças sucessivas que renovaram a fisionomia da natureza(HUMBOLDT, 1952, p. 290).

Além desta produção geográfica sobre a vegetação, Humboldt também faz uma análise térmica importante, procurando compreender a dinâmica de sua distribuição no globo. Reconhece uma relação entre baixas latitudes e as altas temperaturas, estabelecendo um princípio geral de decrescimento da temperatura na direção dos pólos, ao mesmo tempo em que reconhece o fator da altitude como compensador da latitude. Estas ligações pretendem harmonizar-se com a visão da Terra como um todo:

O homem, que sabe abraçar a natureza num só olhar e fazer abstração dos fenômenos particulares, reconhece como, à medida que o calor vivificante aumenta, se desenvolvem gradualmente, dos pólos para o equador, a força orgânica e a potência vital (HUMBOLDT, 1952, p. 283).

Isso também faz parte da construção de uma Geografia Moderna, afinal, estas relações são fundamentais na compreensão da dinâmica climática e na compreensão das características assumidas em cada região.

Ainda vale salientar que Humboldt desenvolve análises sobre as variações regionais das populações, que na verdade ele toma como civilizações, diretamente atreladas à idéia de raça. É larga a denúncia de que Humboldt não se preocupou com o homem em seus trabalhos, compreensão equivocada, ainda que seja clara a limitação de suas interpretações no que se refere às análises diretas que faz das civilizações em sua relação com as regiões. As civilizações são analisadas numa correlação com os climas, mas descarta Humboldt uma supremacia de determinadas raças sobre outras, defende mesmo que não se pode pensar coerentemente acerca da espécie humana se mantida for essa restrita concepção.

Si hemos de mantener el pincípio de la unidad de la espécie humana, necesariamente habemos de desechar como lógica consecuencia e a desoladora distincíon de las razas en superiores é inferiores. Indudablemente hay famílias de pueblos civilizadas mas susceptibles de cultura, mas civilizadas, mas ilustradas que otras: pero nunca mas nobles porque todas han nacido igualmente para la libertad, para esa libertad, que si bien en un estado social poco adelantado no pertenece mas que al indivíduo, es en las naciones llamadas al goce de verdaderas 
instituiciones políticas el derecho de toda la comunidad. (HUMBOLDT, 1874, p. 344-345).

O humano aparece, bem dizer, no plano de análises orgânicas na superfíe terrestre, quer dizer, ele representa, no plano da civilizações e no que se refere a dimensão objetiva, ao elemento orgânico mais bem desenvolvido, que vive e age em interação com a natureza.

Así como la forma esteriormente articulada de los continentes y los innumerables cortes de sur orillas ejercen una saludable influencia en los climas, en el comercio y hasta en los progresos generales de la civilizacion, así tambien la configuracion del suelo en el sentido de la altura, es decir, la articulacion interior de las grandes masas continentales, puede jugar un papel no menos importante en el domínio del hombre. Todo lo que produce variedad de forma (polimorfia) en un ponto de la suuperfície terrestre, ya sea una cadena de montañas, una meseta, un gran lago, una verde estepe, ya tambien um deserto, com bosques por orillas; cualquier accidente del suelo, en una palabra, imprime un sello particular al estado social del pueblo que allí habita. Si está el suelo como entre nevadas y altíssimas cimas, las comunicaciones quedarán interrompidas y el comercio será impossible. Se por el contrario le forman bajas llanuras, com algunas cadenas descontinuas y poco elevadas, como en el Oeste y en el Sud de la Europa, donde este género de articulacion se desarolla tan felizmente, multiplicanse entonces las influencias meteorológicas e com ellas las produciones del mundo vegetal. Y como en tal caso cada region exige un cultivo diferente, aun á la misma latitud, resulta que esta configuracion especial da vida á necessidades que estimulan la actividad de las poblaciones (HUMBOLDT, 1874, p. 280).

É uma análise restrita que procura enquadrar o homem no mesmo princípio de disposições e distribuições que já existe para o esquema das plantas e dos animais. O homem, no que se refere a objetividade geográfica, é reduzido a esse elemento natural, cujos reinos morais se atrelam à natureza. Segundo Humboldt
(1952): "A influência do físico sobre o moral, a ação recíproca e misteriosa do mundo sensível, comunica ao estudo da natureza, feito de um ponto de vista mais elevado, atractivo singular bastante desconhecido até nossos dias." (HUMBOLDT, 1952, p. 286). Como ainda ressalta Capel (1982), Humboldt não caminhou mais na investigação da condição humana em relação com os diferentes espaços, fato que era do seu interesse, pelas diversas restrições políticas como, por exemplo, a que envolve a autorização concedida para seus estudos na Ásia de possessão inglesa e também na Ásia central russa, pelo ministro Conchrin. A preocupação de mascarar os aspectos sociais foi moeda de troca nas concessões para a exploração científica das áreas.

Não obstante se tome o homem por essa medida orgânica e na perspectiva de sua distribuição, ele é mais do que isso, ele é, definitivamente, o misto entre a razão e a sensibilidade, assim como em Schiller; sua condição não é estritamente biológica, ele é atividade do espírito, a idealidade evocada no sistema filosófico do romantismo. Esse homem não pode ser dissociado da natureza, afinal, essa ligação é síntese da dinâmica da realidade; é por ela que completa o homem a atividade natural; é por esta síntese que se dispõe a possibilidade de estender a atividade do espírito em complemento ao processo de realização final da natureza. Logo, quando fala Humboldt em natureza, quando trabalha estas diferentes concepções que culminam num saber geográfico, está falando também do humano; não numa perspectiva do homem "sociedade", mas a do homem elemento de síntese, parte mesmo do processo de construção natural.

Ainda numa perspectiva direta de análise, não pode dissociar-se o desafio que Humboldt se coloca na descrição física do mundo daquilo que ele denomina Geografia Física. Esta Geografia Física é a representação do projeto de ciência cósmica no limite das relações terrestres, segundo seus princípios, leis e particularidades. Aqui, a Geografia é síntese de múltiplos fenômenos e de inúmeros ramos específicos do saber, aquilo mesmo que hoje criticamos como o ponto 
limitador da Geografia em sua história. Essa Geografia Física é, ainda segundo entendemos, também Geografia, a despeito da análise de Capel (1982), que defende a ideia de que essa Geografia está distante do que se construiu depois e do que até então se havia construído; nessa visão, os propósitos deste saber não seriam geográficos, mas ligados estritamente a esta descrição física do mundo que, por simples herança de Saussure, assume o nome de Geografia Física. Imprecisa, essa análise mascara o fato de que a construção proposta é uma construção geográfica, independente do valor semântico dado ao termo Geografia e mesmo à ligação desta com outra fonte diversa daquela proposta até então pelos rumos da ciência.

Aqui entra aquele segundo ponto importante, o de que as ciências não nascem de si mesmas, mas de esforços diversos, que se agrupam sob nova feição e segundo leituras e metodologias próprias. Embora isso pareça óbvio, é importante destacar esse ponto, porque Capel (1982) o ignora quando afirma que "com sua física do globo Humboldt não estava fundamentando a geografia moderna, senão esforçando-se em estabelecer uma ciência totalmente nova, que pouco tinha a ver com a geografia da época." (CAPEL, 1982, p.16-17). Ora, ela não tinha nada que ver com o que estava sendo construído até então sob o nome de Geografia justamente pelo fato de que é uma nova formulação, que, atendendo inclusive pelo nome de Geografia Física, representa um passo decisivo para a construção sistemática de um saber geográfico moderno. De todo modo, reforçamos o óbvio, as ciências em sua gênese não surgem a partir de si mesmas, mas de uma série de elementos intelectuais e materiais. A respeito desta Geografia Física Humboldt nos fala:

No se trata en este ensayo de reducir el conjunto de los fenómenos sensibles á un pequeño número de princípios abstractos, sin mas base que la razon pura. La física del mundo que yo intento esponer, no tiene a pretension de elevarse á las peligrosas abstraciones de una ciencia meramente racional de la naturaleza; es una 'geografia física' reunida á la descripcion de los espacios celestes y de los cuerpos que llenan esos espacios (HUMBOLDT, 1874, p. 29).

Comparando diferentes partes e reconhecendo-Ihes a unidade, valendo-se tanto dos dispositivos da ciência em voga, como das bases de uma filosofia da natureza no romantismo, Humboldt cumpre uma análise geográfica de síntese, ou holística como destaca Moreira (2006). A Geografia Física de Humboldt é voltada para todas as contribuições científicas, sejam quais forem às áreas que se delimitem no estudo de cada particular dado; sua ciência está para além das fronteiras e se vale, paradoxalmente, dos frutos e contribuições dos diferentes ramos especializados do saber. A Geografia Física é, portanto, o ponto de encontro e entendimento das relações e conexões no nível terrestre; a unificação científica dos domínios orgânicos e inorgânicos; a junção da subjetividade com a objetividade na análise da natureza. Moreira (2006) citando Humboldt (MOREIRA, 2006, p. 23, apud TATHAM, 1959, p. 216) deixa claro o que é esta Geografia:

Minha atenção estará sempre voltada para a observação da harmonia entre as forças da natureza, reparando a influência exercida pela criação inanimada sobre o reino animal e vegetal. Deve ser lembrado, entretanto, que a crosta inorgânica da terra contém dentro de si os mesmos elementos que entram na estrutura dos órgãos animal e vegetal. Por conseguinte, a cosmografia física seria incompleta se omitisse considerações dessa importância, e das substâncias que entram nas combinações fluidas dos tecidos orgânicos, sob condições que, em virtude de ignorarmos a sua natureza real, designamos pelo termo vago de "forças vitais", grupando-as dentro de vários sistemas, de acordo com analogias mais ou menos perfeitamente concebidas. A natural tendência do espírito humano, involutariamente, nos impele a seguir os fenômenos físicos da terra através de toda a velocidade de suas fases, até atingirmos a fase final da solução morfológia das formas vegetais, e os poderes conscientes do movimento do organismo dos animais. 
Assim, é por tais elos que a geografia dos seres orgânicos - plantas e animais - se liga com os esforços dos fenômenos inorgânicos de nosso globo terrestre (MOREIRA, 2006,p. 23).

Quando se coloca no plano histórico uma divisão dessa ciência que nasce sintética, a tentativa é dar formas mais definidas e um recorte mais apropriado e preciso para uma ciência que nasce como síntese de todas as contribuições das ciências. A ruptura que se coloca também é fruto de uma leitura equivocada do projeto de ciência humboldtiano. Gomes (2000) coloca a dualidade da Geografia na sua gênese em Humboldt, mas não é dele que essa dualidade emerge, antes disso, é da incompreensão do seu projeto de ciência que surge a dualidade no saber geográfico. Para Humboldt, assim como para Kant, não há qualquer possibilidade de se dissociar os elementos descritivos das conexões, das relações que são, em última instância, elementos estruturantes da própria diferenciação. $\mathrm{Na}$ não observação desse princípio unificador elementar entre todo e partes, entre descrição e estabelecimento de leis, é que se encontram os caminhos de uma Geografia ideográfica e outra nomotética. Isso não está em Humboldt, nele tudo é síntese, e descrever não pode nunca ser dissociado das conexões, mesmo porque o método que intenta é comparativo, ou seja, valese dos particulares para encontrar a unidade e, mais do que isso, pressupõe a abrangência do seu método que o próprio ato de descrever é, pela linguagem proso-poética como medium-dereflexão, um salto para a compreensão geral, o reconhecimento de uma integração que não pode ser dada pelo esquartejamento analítico a partir de uma linguagem estritamente científica. Separar descrição e leis é acabar com qualquer continuidade da ciência humboldtiana; igualmente, cingir o humano e a natureza é caminhar para longe do que é Geografia em Humboldt, afinal, como fizemos questão de salientar em diversas oportunidades, a natureza não pode, pelo papel que desempenha em seus trabalhos e no movimento romântico, ser pensada em separado do homem, enfim, não pode haver qualquer análise da natureza sem reconhecer e emprestar a ela o que de humano há no sujeito que a interroga. Em poucas palavras, o curso histórico do conhecimento geográfico, suas dualidades e inconsistências são um contínuo relutar com essa origem abandonada, esse esquecido desafio filosófico de síntese que ocupou a Geografia em sua gênese moderna em Humboldt.

$\mathrm{Na}$ apresentação dessa análise já demonstramos indiretamente a reposta para um pergunta fundamental, bem seja: o Cosmos de Humboldt, enquanto um todo, pode ser considerado um trabalho geográfico? É evidente que ele se vale de inúmeras ciências e aqui sem polêmicas, ele mesmo não reconhece como estritamente geográfica a sua proposta, contudo, a resposta dada ao que então concebemos como Geografia nos autoriza a interpretar o projeto de ciência humboldtiana como um trabalho geográfico. Por compreendermos a Geografia como uma ciência que procura analisar a natureza em suas relações, bem como destas com o homem numa perspectiva abrangente de espaço, temos que o Cosmos é Geografia. E mais, a sua construção oferece, pela medida de síntese, uma resposta científico-filosófica-artística para o problema da dualidade entre Geografia Física e Geografia Humana, bem como alenta a dupla relação necessária e aberta entre a subjetividade e a objetividade. Portanto, a despeito do nome que se atribua a esta ciência, ela é, por reduzir e pensar em termos de relações espaciais o conjunto dinâmico da realidade, sobretudo da natureza, em harmonia com as dimensões subjetivas e objetivas, uma construção geográfica.

Essa leitura encerra a ideia de que Humboldt é fundamental para a Geografia:

a) pela estruturação de uma ciência com objeto, método e metodologias que atuam em conformidade e segundo um objetivo específico, ainda que, no caso de Humboldt, confluam para uma síntese filosófica;

b) por mobilizar na nossa história científica esforços que produziram, mesmo que a partir de interpretações equivocadas, construções descritivas e busca por conexões causais, e 
c) por apresentar-se ao saber geográfico contemporâneo com uma resposta de síntese para o problema da dualidade entre uma Geografia Física e uma Geografia Humana, bem como para a tarefa de confluir harmonicamente objetividade e subjetividade no corpo da atividade científica, indo, definitivamente, ao ponto central da necessidade contemporânea de se pensar em unidade e transcender os limites restritos das disciplinas formais.

\section{Considerações: a obra de Humboldt e a Geografia Contemporânea}

Pontuamos algumas questões que dizem respeito às dificuldades que envolvem a produção no campo da ciência geográfica. Como fizemos questão de destacar, estes problemas, assentados na necessidade de uma nova visão integradora, não são estritamente geográficos, as ciências experimentam a dificuldade de lidar com as especializações e os entraves colocados ao conhecimento. Por um lado, essa fragmentação foi e é importante no cumprimento de objetivos claros e pragmáticos, bem como para a ampliação de um corpo de informações como nunca antes imaginado. Por outro lado, o rumo da construção por esse contínuo fragmentar e analisar recobra o sentido filosófico na explicação geral dos fenômenos, na compreensão legítima dos processos que fogem aos limites disciplinares e às fronteiras sob as quais se entrincheiraram as ciências em seus interesses corporativos e institucionais. No reduto desta discussão se abrem as questões para um pensar e um diálogo interdisciplinar, procurando esclarecer e apontar caminhos de integração dos diferentes ramos e campos de pesquisa. A dificuldade central reside no fato de que os campos científicos foram construídos com base em sistemas e premissas filosóficas distintas. Quando se dá definitivamente, com o aporte filosófico da teoria kantiana, a separação entre ciência e filosofia, quando pode a atividade científica alçar seus vôos sem recorrer a todo instante ao inibidor processo de investigação filosófica.
O passo derradeiro para o avanço de uma ciência que reencontra a filosofia só na adoção dos princípios e pressupostos, bem como para a validação do método e para o arranjo coerente da sua estrutura. Nesse sentido, a filosofia tornase um cabedal de conceitos e estruturas escolhidas ao gosto do freguês, melhor dizendo, segundo o interesse analítico de cada ramo do saber científico. Não se busca a verdade, buscase a produção de um conhecimento com validade restrita ao universo de premissas adotadas. Logo, quando se apresenta uma dificuldade qualquer no rumo do conhecimento, a tarefa de reinventarse a partir do método torna-se um desafio cada vez mais difícil. As ciências, experimentando a limitação que, em verdade, é tão somente o resultado desse exaustivo aprofundar específico, clamam por uma visão geral, uma articulação não construída, sobretudo porque a própria filosofia tornou-se ciência. Como não interessa à realidade o fato de estarmos ou não munidos para superar as dificuldades impostas à sua investigação, provamos do revés de nosso avanço, a limitação imposta por aquilo que nos fez outrora caminhar, ou seja, a fragmentação.

Em Humboldt podemos encontrar algumas questões que suscitam debate e, mesmo, que ensejam algumas respostas. Em primeiro lugar, por não se preocupar em fundamentar um conhecimento geográfico, Humboldt o construiu de uma maneira inovadora e, ao seu período, eficiente. Aqui, no nosso contexto, cabe-nos pensar o mundo com o mesmo olhar desafiador e irrestrito, porque é só ele que fornecerá as ferramentas e as reflexões que permitirão um estender de horizontes. Em segundo lugar, Humboldt articulou um múltiplo legado e, o que é mais difícil, de maneira coerente. A possibilidade de se agrupar os frutos de uma ciência racionalista com as contribuições de uma Naturphilosophie romântica, para qualquer conhecedor do tema, parece uma tarefa impossível, que, no entanto, resultou frutífera pelas mãos de Humboldt. Aqui, ao nosso tempo, vale esta contribuição num cenário que anuncia novas posturas cognitivas e metodológicas, um cenário que evoca um permear e um diálogo de saberes para além de suas fronteiras institucionais. É importante 
reconhecer uma contribuição fundamental de Humboldt, a que define como imprescindível os rumos de todo saber acumulado pelo humano. Nessa proposta de inspiração schellinguiana, encontramos o aviso necessário de que, por mais que seja limitado e restritivo este universo de especializações, ele não deve ser abandonado, mas incorporado no rumo final de uma forma de saber mais apropriada. Isso é fundamental e talvez seja o ponto principal na forma com que Humboldt procura tratar sua ciência. Sem demora, devemos reconhecer que o que foi acumulado até aqui pela atividade do homem não pode ser esquecido ou lançado ao fogo como marca de um tempo descabido e desarticulado, ao contrário, deve aparecer à luz de uma nova postura diante do saber. Mais do que pelo conteúdo, o valor do trabalho de Humboldt está na forma, e mais do que na forma que ele empregou, está seu valor nas formas que pode ainda suscitar.

Obviamente que as considerações de Humboldt não podem ser trazidas sem qualquer consequência para o século XXI, igualmente, as construções filosóficas que permitiram seu reagrupar metodológico já passaram por um crivo de duras investidas que, no mínimo, devem ser consideradas no bom andamento de uma solução ou na colocação de um apontamento mais específico para a ciência. Humboldt materializou e ao mesmo tempo instrumentalizou a concepção de integração dinâmica das esferas da natureza, que redundou em seu conceito de espacialidade e na fundamentação metafísica de uma Terra e um Mundo que estavam em transformação e, agora, em constante mutação, em um processo de transformações em forma espiral e com crescente e acumulada complexidade, de tal forma que hoje podemos inventar a natureza e a vida.

Fica, pois, um desafio à Geografia, que nesse início de novo século enfrenta problemas de todas as ordens, mas que talvez o maior de todos seja o dar conta de uma nova fundamentação filosófica a essa nova Terra e Mundo que está em construção e que nos desaloja de nossos casulos existenciais e nos interroga sobre a possibilidade da existência da própria ciência geográfica.

\section{Bibliografia}

BEISER, Frederick. Schiller: as philosopher. Oxford: Claredon Press, 2005.

BOWEN, Margarita. Empiricism and geographical thought: from Francis Bacon to Alexander von Humboldt. London: Cambridge University Press, 1981.

CAPEL, Horácio. Filosofía y ciencia en la geografía Contemporanea. Barcelona: Temas Universitários, 1982.

CLAVAL, Paul. História da Geografia. Porto: Edições 70, 2000.

DIECKMANN, Liselotte. (translation). Correspondence between Goethe and Schiller 1794-1805. New York: Peter Lang, 1994.

GAYET, Mireille. Alexandre de Humboldt: le dernier savant universel. Paris: Vuibert-Adapt, 2006.
GLACKEN, Clarence. Huellas en la playa de rodas. Barcelona: Ediciones del Serbal, 2006.

GOETHE, Johann W. Sämtliche Werke. Zurich: Artemis Verlag, Band 7, 1977.

GOETHE, Johann W. Teoría de la naturaleza. (Trad. Diego Sánches Meca). Madrid: Tecnos, 1997.

GOETHE, Johann W. Máximas e Reflexões. Col. Obras Escolhidas. (Trad. José M. Justo). Lisboa: Relógio D'água Editores, 2000.

GOMES, Paulo Cesar da Costa. Geografia e Modernidade. Rio de Janeiro: Bertrand Brasil, 2000.

HELFERICH, Gerard. O Cosmos de Humboldt. Rio de Janeiro: Objetiva, 2004.

HUMBOLDT, Alexander von. Cosmos. Essai d'une description physique du monde. Paris: gide et J. Baudry Éditeurs, 1874, 4 vols. 
HUMBOLDT, Alexander von. Quadros da natureza. Rio de Janeiro-Porto: Editores W.W.Jackson INC, 1952.

KANT, Imannuel. Primeiros princípios metafísicos da ciência da natureza. Lisboa: Edições 70, 1990. - Crítica da faculdade de julgar. RJ: Forense Universitária, 1995.

Crítica da razão pura. Lisboa: Fundação Gulbenkian, 1999.

LIVINGSTONE, David. The Geographical Traditional. New York: Blackwell, 1992.

MENDOZA, Josefina. Alejandro de Humboldt y la Geografía Del Paisaje. In: Holl, Frank (Ed.) Alejandro de Humboldt: uma nueva visión del mundo.Madrid: Museo Nacional de Ciencias Naturales de Espanã-Embajada de Alemania. 2006, p. 55-64.

MOREIRA, Ruy. Para onde vai o pensamento geográfico? São Paulo: Editora Contexto, 2006.

RICOTTA, Lúcia. Natureza, ciência e arte em Alexander von Humboldt. Rio de Janeiro: Mauad, 2003.
SHARPE, Lesley. The Cambridge Companion to Goethe. Cambridge: Cambridge University Press, 2000.

SCHIEREN, Jochen. Anschauende Urteilskraft. Methodische und philosophische Grundlangen von Goethes naturwiessenschaftlichem Erkennen Dusseldorf. Bonn: Parerga, 1998.

STAFFORD, Barbara Maria. Voyage in to substance. Art, science, nature, ant the ilustrated travel account, 1760-1840. Cambridge: MIT Press, 1984.

SILVEIRA, Roberison W. D. da. Influências da filosofia kantiana e do movimento romântico na Gênese da Geografia Moderna: a constituição dos conceitos de espaço, natureza e morfologia em Alexander von Humboldt. Campinas, 2008. Dissertação (Mestrado em Geografia). Instituto de geociências, Unicamp.

VALADÃO, Claudia. Hackert e Geothe e a pintura de paisagens. São Paulo: Ateliê Editorial, 2008.

VITTE, Antonio Carlos. A terceira crítica kantiana e sua influência no moderno conceito de geografia física. GEOUSP, São Paulo, 19, 2006, p. 33-52. 